\title{
MANEJ O De Bidens subalternans Resistente AOS HeRBICIDAS INIBIDORES DA ACETOLACTATO SINTASE ${ }^{1}$
}

\author{
Management of Bidens subalternans Resistant to Acetolactate Synthase Inhibitor Herbicides
}

\author{
GAZZIERO, D.L.P. ${ }^{2}$, PRETE, C.E.C. ${ }^{3}$ e SUMIYA, M. ${ }^{4}$
}

\begin{abstract}
RESUMO - A extensão das áreas com seleção de populações de plantas daninhas resistentes a herbicidas tem aumentado rapidamente no Brasil nos últimos anos, sendo citado como causa principal desta seleção a recomendação inadequada de produtos. Com o objetivo de avaliar a eficácia de controle de plantas daninhas através de herbicidas, com diferentes mecanismos de ação, sobre plantas de Bidens subalternans, foi conduzido o presente trabalho, que envolveu um experimento de casa de vegetação e dois de campo, com as culturas de milho e soja. A pesquisa foi realizada a partir de populações de plantas de Bidens subalternans com suspeita de resistência aos herbicidas inibidores da ALS encontradas em área de produção comercial nas quais ocorriam falhas de controle através desses herbicidas. Os resultados permitiram confirmar a seleção de populações resistentes aos herbicidas inibidores da acetolactato sintase (ALS) e encontrar alternativas para o manejo destas populações, por meio do uso de produtos com mecanismo de ação diferenciado, tanto para a cultura da soja quanto para a do milho. Produtos inibidores da protoporfirinogênio oxidase (PROTOX), da fotossíntese e da divisão celular, aplicados isoladamente ou em misturas, controlaram adequadamente o biótipo resistente.
\end{abstract}

Palavras-chave: picão-preto, planta daninha, mecanismo de ação, ALS, PROTOX.

ABSTRACT - The acreage with herbicide resistant weed populations has rapidly increased in Brazil in recent years. Inadequate herbicide recommendation is pointed as the main cause of this problem. This study aimed to evaluate Bidens subalternans control efficacy through herbicides with alternative mechanisms of action, consisting of a greenhouse and two field experiments, with corn and soybean crops. A Bidens subalternans population suspected to be resistant to ALS inhibitor herbicides, found in a commercial crop area, was used in the experiments. The results confirmed beggartick resistance to $A L S$ inhibitor herbicides. Management alternatives found for this weed include herbicides recommended for soybean and corn with differentiated mechanism of action: protoporphyrinogen oxidase (PROTOX) inhibitors, mitotic disrupters and photosynthesis inhibitor herbicides, applied alone or in tank mixture.

Key words: beggartick, weed resistance, mechanism of action, ALS, PROTOX.

\section{INTRODUÇÃO}

Os primeiros casos de resistência de plantas daninhas no Brasil foram documentados por Christoffoleti et al. (1996), Ponchio et al. (1996) e Vidal \& Fleck (1997), com as espécies Bidens pilosa, Euphorbia heterophylla e Brachiaria plantaginea, envolvendo produtos inibidores das enzimas acetolactato sintase (ALS) e acetilcoenzima A carboxilase (ACCase). Gazziero et al. (1997, 1998a) relataram a ocorrência de biótipos de B. plantaginea e E. heterophylla no Estado do Paraná em áreas com uso contínuo de produtos com os mesmos mecanismos de ação. Biótipos de outras duas espécies (Sagitaria montevidensis e Echinochloa

Recebido para publicação em 8.1.2002 e na forma revisada em 11.8.2003.

2 Eng.-Agr., Doutorando da UEL. Pesquisador da Embrapa Soja, Caixa Postal 231, 86001-970 Londrina-PR, <gazziero@cnpso.embrapa.br>; ${ }^{3}$ Eng.-Agr., Professor da UEL, <cassio@uel.br>; ${ }^{4}$ Estagiário Embrapa/UEL, Graduando de Agronomia/UEL, <agrosumiya@zipmail.com.br>.

Planta Daninha, Viçosa-MG, v.21, n.2, p.283-291, 2003 
crus-galli) e E. crus-pavonis também foram documentados como resistentes, em áreas de arroz irrigado (Noldin et al., 2000; Eberhard et al., 2000; Merotto Jr. et al., 2000). A principal causa da resistência aos inibidores da ALS é a presença de isoenzimas de ALS, insensível à ação dos herbicidas (Vidal, 1997). A ALS catalisa a primeira reação na produção dos aminoácidos de cadeia ramificada, valina, leucina e isoleucina. Após a absorção, esses herbicidas são rapidamente translocados para a área de crescimento ativo (meristema, ápices), inibindo o desenvolvimento. As plantas acabam morrendo, devido à incapacidade de produzir os aminoácidos essenciais de que necessitam (Oliveira Jr., 2001). Vários grupos químicos de herbicidas têm como característica a inibição da ação desta enzima, dentre os quais são citadas as sulfoniluréias, as imidazolinonas, as sulfonanilidas e os pirimidil tiobenzoatos (Trezzi \& Vidal, 2001). A mutação na enzima ALS responsável pela resistência é nuclear e, no mínimo, parcialmente dominante, sendo transmitida por semente e pólen. Outras causas atribuídas à resistência contemplam fatores ligados ao amplo uso desses produtos, à forma como são utilizados e à pressão de seleção (Tranel \& Wright, 2002). Esses grupos incluem produtos para as culturas da soja, do milho e do trigo, entre outras, as quais são utilizadas em sucessão ou em rotação, dentro de uma mesma área, aumentando a pressão de seleção, caso não sejam adotadas medidas técnicas adequadas.

Atualmente, observam-se freqüentes relatos sobre manifestações de resistência pelos agentes de assistência técnica. É possível que esteja havendo aceleração no processo de disseminação de biótipos resistentes, especialmente na Região Sul do Brasil, devido ao aluguel de colhedoras, o que é uma prática comum entre agricultores, em razão do tamanho médio das propriedades. No entanto, reconhecidamente, a pressão de seleção é a principal responsável pela manifestação da resistência, a qual é favorecida pelo uso continuado de produtos com o mesmo mecanismo de ação (Vidal, 1997). Programas de prevenção e manejo da resistência incluem várias práticas agrícolas (Christoffoleti et al., 1994; SBCPD, 2000; Gazziero et al., 2001). Contudo, a rotação de produtos e a mistura de produtos com mecanismo de ação diferenciado são as alternativas mais eficientes para solucionar o problema (Powles \& Howat, 1990). Bidens subalternans ocorre freqüentemente no Estado do Paraná (Gazziero et al., 1998a). A resistência dessa planta daninha aos inibidores da ALS foi relatada por Monqueiro et al. (2000). Essa espécie, em regiões quentes, chega a produzir três a quatro gerações, no período de um ano. Segundo Kissmann \& Groth (1993), trata-se de uma planta nativa da América do Sul, com ciclo de vida anual e muito parecida com Bidens pilosa. Em áreas altamente infestadas, esta espécie chega a reduzir a produtividade da soja em $30 \%$.

Este trabalho teve como objetivos confirmar a ocorrência de população de picão-preto resistente aos herbicidas inibidores de ALS e, também, selecionar produtos com diferentes mecanismos de ação recomendados para a cultura da soja e do milho, eficientes no controle desse biótipo resistente.

\section{MATERIAL E MÉTODOS}

Este trabalho constou de experimentos desenvolvidos na safra de 2000/2001, em condições de casa de vegetação e de campo, em uma área de produção comercial, com suspeita da presença de picão-preto resistente aos herbicidas inibidores da enzima ALS. O biótipo foi identificado como Bidens subalternans e cadastrado como BIDSU-101. O histórico dessa área indicava falhas no controle e o uso continuado de herbicida com o mesmo mecanismo de ação. Foi utilizado um produto do grupo químico das imidazolinonas - imazaquin - por sete anos, seguido por outro período de cinco anos de aplicação continuada da combinação dos pós-emergentes imazethapyr + chlorimuron, do grupo químico das imidazolinonas e sulfoniluréias, respectivamente, e um ano com o produto diclosulan, do grupo químico das sulfonanilidas.

\section{Experimento de casa de vegetação}

Neste experimento foram utilizadas sementes de picão-preto provenientes de uma área com suspeita de resistência, a qual havia sido previamente pulverizada com a mistura imazethapyr + chlorimuron (ALS + ALS) em pós-emergência, em setembro de 2000, e também de uma área não-agricultável, na qual 
nunca havia sido aplicado herbicida. O procedimento objetivou confirmar preliminarmente a suspeita de resistência e baseou-se no documento que trata da identificação e do manejo de plantas resistentes aos herbicidas, proposto pela Sociedade Brasileira da Ciência das Plantas Daninhas (SBCPD, 2000). Utilizou-se delineamento experimental em blocos ao acaso e quatro repetições. O trabalho foi conduzido em casa de vegetação, tendo sido iniciado em dezembro de 2000, em Londrina-PR, com os tratamentos descritos na Tabela 1. Vasos de $3.500 \mathrm{~cm}^{3}$, contendo três partes de solo e uma de material orgânico, foram preparados para semeadura com 30 sementes de picão-preto por vaso, permanecendo dez plantas após o desbaste. As sementes de plantas teoricamente suscetiveis e aquelas com suspeita de resistência foram semeadas em vasos separados. Foi utilizado pulverizador de precisão a $\mathrm{CO}_{2}$, regulado para volume de pulverização de $200 \mathrm{~L}$ ha $^{-1}$ de calda, pressão de $40 \mathrm{lb} \mathrm{pol}^{-2}(275 \mathrm{kPa}) \mathrm{e}$ equipado com bico 80.02 VS. As aplicações foram feitas no estádio de três a quatro folhas e as avaliações ocorreram 15 dias após, utilizando-se escala percentual de 0 a 100, em que 0 significou nenhum controle e 100\%, controle total. Após a avaliação foi determinado o peso da biomassa seca acumulada (Tabela 1).

\section{Experimentos de campo}

A fim de complementar as informações sobre as alternativas para manejo de herbicidas, foram conduzidos dois experimentos a campo, sendo um com a cultura do milho e outro com a da soja. Eles foram instalados em Sertaneja$\mathrm{PR}$, em uma área onde havia sido aplicado imazethapyr + chlorimuron na dose recomendada, em setembro de 2000. Esse procedimento foi adotado para proporcionar maior seleção do biótipo resistente. Os experimentos foram conduzidos no sistema de semeadura direta, sendo utilizado $1,58 \mathrm{~kg}$ de glyphosate para o manejo do picão-preto que havia germinado antes da semeadura das culturas.

Tabela 1 - Alternativas de herbicidas para o controle de picão-preto (Bidens subalternans), resistente aos inibidores da enzima ALS. Experimento conduzido em casa de vegetação. Embrapa Soja. Londrina-PR. 2001

\begin{tabular}{|c|c|c|c|c|c|c|}
\hline Tratamento & $\begin{array}{l}\text { Mec. de } \\
\text { Ação }^{2 /}\end{array}$ & $\begin{array}{c}\text { Dose } \\
\left(\mathrm{kg} \mathrm{ha}^{-1}\right)\end{array}$ & $\mathrm{R} / \mathrm{S}^{-3 /}$ & Uso & $\begin{array}{c}\text { Controle } \\
(\%)\end{array}$ & $\begin{array}{c}\text { Biomassa Seca } \\
\text { (g/10 plantas) }\end{array}$ \\
\hline 1. sulfentrazone & Protox & $\overline{0,6}$ & $\overline{\mathrm{R}}$ & PRÉ & $100,00 \mathrm{a}^{4 /}$ & $0,00 \mathrm{f}^{-4}$ \\
\hline 2. diclosulan & ALS & 0,035 & $\mathrm{R}$ & PRÉ & $5,00 \mathrm{c}$ & $2,06 \mathrm{~cd}$ \\
\hline 3. diclosulan & ALS & 0,141 & $\mathrm{R}$ & PRÉ & $10,00 \mathrm{~b}$ & $1,54 \mathrm{de}$ \\
\hline 4. fomesafen ${ }^{-1}$ & Protox & 0,25 & $\mathrm{R}$ & PÓS & $100,00 \mathrm{a}$ & 0,00 ef \\
\hline 5. oxasulfuron ${ }^{-1}$ & ALS & 0,02 & $\mathrm{R}$ & PÓS & $5,00 \mathrm{c}$ & $3,54 \mathrm{~b}$ \\
\hline 6. oxasulfuron ${ }^{-1}$ & ALS & 0,08 & R & PÓS & $10,00 \mathrm{~b}$ & $2,99 \mathrm{bc}$ \\
\hline 7. lactofen & Protox & 0,16 & $\mathrm{R}$ & PÓS & $100,00 \mathrm{a}$ & $0,00 \mathrm{ef}$ \\
\hline 8. oxasulfuron + fomesafen & ALS + Protox & $0,015+0,2$ & $\mathrm{R}$ & PÓS & $99,33 \mathrm{a}$ & 0,74 ef \\
\hline 9. oxasulfuron + lactofen & ALS + Protox & $0,012+0,12$ & $\mathrm{R}$ & PÓS & $100,00 \mathrm{a}$ & 0,00 ef \\
\hline 10. sulfentrazone & Protox & 0,6 & S & PRÉ & $100,00 \mathrm{a}$ & $0,00 \mathrm{f}$ \\
\hline 11. diclosulan & ALS & 0,035 & S & PRÉ & $99,33 \mathrm{a}$ & $0,02 \mathrm{f}$ \\
\hline 12. oxasulfuron & ALS & 0,02 & S & PÓS & $100,00 \mathrm{a}$ & $0,00 \mathrm{f}$ \\
\hline 13. lactofen & Protox & 0,16 & S & PÓS & $100,00 \mathrm{a}$ & 0,00 ef \\
\hline 14. chlorimuron & ALS & 0,02 & S & PÓS & $100,00 \mathrm{a}$ & $0,00 \mathrm{f}$ \\
\hline 15. oxasulfuron + lactofen & ALS + Protox & $0,012+0,096$ & S & PÓS & $100,00 \mathrm{a}$ & $0,00 \mathrm{f}$ \\
\hline 16. testemunha & & - & $\mathrm{R}$ & - & $0,00 \mathrm{~d}$ & $5,25 \mathrm{a}$ \\
\hline 17. testemunha & & - & S & - & $0,00 \mathrm{~d}$ & $4,07 \mathrm{~b}$ \\
\hline $\mathrm{CV} \%$ & & & & & 0,74 & 28,10 \\
\hline DMS $5 \%$ & & & & & 1,517 & 1,149 \\
\hline
\end{tabular}

1/ Surfatante Agral 0,2\% v/v. ${ }^{2} /$ ALS - inibidores da enzima acetolactato sintase; Protox - inibidores da protoporfirinogênio oxidase. ${ }^{3 /} \mathrm{R}=$ plantas com suspeita de resistência; $\mathrm{S}=$ plantas suscetíveis. ${ }^{4 /}$ Médias seguidas pela mesma letra, na coluna, não diferem entre si pelo teste de Tukey $(\mathrm{P}<5 \%)$. 


\section{a) Experimento de campo - milho}

A instalação do experimento com milho foi em 28 de novembro de 2000 e, no mesmo dia, foram aplicados os tratamentos de préemergência (Tabela 2). Durante as aplicações registrou-se temperatura de $30{ }^{\circ} \mathrm{C}$, umidade relativa de $50 \%$ e ventos variando de 4 a $10 \mathrm{~km} /$ hora. Trinta dias após foram aplicados os tratamentos em pós-emergência (Tabela 2), com pulverizador de precisão a $\mathrm{CO}_{2}$, bicos Teejet 80.02 VS, num volume de calda de $200 \mathrm{~L} \mathrm{ha}^{-1}$. Registrou-se temperatura de $29^{\circ} \mathrm{C}$, $60 \%$ de umidade relativa do ar e ventos de 4 a $10 \mathrm{~km} /$ hora. As plantas de picão-preto estavam com duas a quatro folhas, em média. $O$ delineamento experimental foi o de blocos ao acaso, com quatro repetições e parcelas de $2,5 \times 10 \mathrm{~m}$. As avaliações visuais de fitointoxicação e controle foram feitas utilizando escala percentual de 0 a 100, conforme já descrito (Tabela 2). Aos 20 dias após a aspersão dos herbicidas de aplicação em pós-emergência, foi realizada avaliação da altura das plantas de picão-preto, da biomassa seca e, no final do ciclo, do rendimento do milho (Tabela 3).

\section{b) Experimento de campo - soja}

Em 27 novembro de 2000 foi semeado o experimento com a cultura da soja, utilizando-se o cultivar BRS-133. No mesmo dia foram aplicados os herbicidas pré-emergentes, com equipamento de precisão a $\mathrm{CO}_{2}$, com bicos Teejet $80.02 \mathrm{VS}$, pressão de $40 \mathrm{lb} \mathrm{pol}^{-2}$ e volume de calda de $200 \mathrm{~L} \mathrm{ha}^{-1}$. Registrou-se $31{ }^{\circ} \mathrm{C}$ de temperatura, $50 \%$ de umidade relativa do ar e ventos de $4 \mathrm{~km} \mathrm{~h}^{-1}$, com rajadas de até $10 \mathrm{~km} \mathrm{~h}^{-1}$. Os tratamentos são apresentados na Tabela 4. Os herbicidas de aplicação em pós-emergência foram pulverizados em duas épocas. Vinte e quatro dias após a emergência foi realizada a primeira etapa da aplicação seqüencial, com o mesmo equipamento descrito anteriormente. Registrou-se nessa ocasião temperatura de $29{ }^{\circ} \mathrm{C}$ e $60 \%$ de umidade relativa do ar. A soja estava no estádio $\mathrm{V}_{4}$ e as plantas de picão-preto com duas folhas. Aos 33 dias da emergência foi feita a segunda aplicação (seqüencial). Nessa ocasião também foram aspergidos os demais tratamentos de aplicação em pós-emergência, utilizando-se os mesmos equipamento e regulagem já descritos.
A soja se encontrava no estádio $\mathrm{V}_{6}$ e as plantas de picão-preto estavam com quatro folhas em média. O delineamento experimental foi o de blocos ao acaso, com quatro repetições e parcelas de $2,0 \mathrm{~m} \times 10 \mathrm{~m}$. As avaliações visuais foram feitas adotando-se escala percentual de 0 a 100, já descrita (Tabela 4). O número de plantas $\mathrm{m}^{-2}$, a altura das invasoras e a biomassa seca foram determinados 20 dias após a segunda etapa de aplicação dos tratamentos em pós-emergência e 49 dias após os de pré-emergência. No final do ciclo da cultura foi determinado o rendimento em $\mathrm{kg} \mathrm{ha}^{-1}$ (Tabela 5).

\section{RESULTADOS E DISCUSSÃO}

Na casa de vegetação, os resultados mostraram baixa eficiência de controle do picãopreto com suspeita de resistência, ao se utilizarem herbicidas inibidores da ALS. Inibidores da PROTOX permitiram atingir níveis esperados de controle sobre plantas do mesmo grupo. Na dose recomendada dos herbicidas diclosulan e oxasulfuron ou quatro vezes essa dose, não foi possivel obter controle do biótipo com suspeita. No entanto, ao utilizar sulfentrazone, lactofen ou mesmo oxasulfuron, em mistura com lactofen e fomesafen, os resultados atingiram valores de $100 \%$ de controle. Diclosulan e oxasulfuron, em doses consideradas normais nas plantas tidas como suscetiveis, produziram excelentes resultados. O aumento em até quatro vezes na dose dos produtos inibidores da ALS não reduziu a biomassa acumulada das plantas resistentes (Tabela 1). Entre as estratégias citadas para prevenir e manejar casos de resistência inclui-se a rotação de herbicidas com mecanismo de ação diferenciado (Vidal, 1977; Gazziero et al., 2001; Vargas et al., 1999; SBCPD, 2000). Uma planta que manifestou resistência a um determinado mecanismo de ação pode ser controlada por outros produtos, desde que possuam mecanismo de ação diferenciado (Powles \& Howat, 1990), ou pela mistura de produtos, desde que um deles atenda a esse pressuposto. Os resultados encontrados no experimento em casa de vegetação confirmaram as suspeitas levantadas por ocasião da realização do histórico da área. Resultados semelhantes em experimento conduzido com populações de Bidens pilosa e Bidens subalternans foram encontrados por Monqueiro \& Christoffoleti (2001). 
Tabela 2 - Tratamentos utilizados e avaliação visual da eficácia de herbicidas aplicados em pré e pós-emergência na cultura do milho, no controle de picão-preto (B. subalternans). Experimento de campo. Sertaneja-PR. Embrapa Soja. Londrina-PR. 2001

\begin{tabular}{|c|c|c|c|c|c|c|c|}
\hline \multirow{2}{*}{ Tratamento } & \multirow{2}{*}{$\begin{array}{l}\text { Mec. de } \\
\text { Ação }^{1 /}\end{array}$} & \multirow{2}{*}{$\begin{array}{c}\text { Dose } \\
\left(\mathrm{kg} \mathrm{ha}^{-1}\right)\end{array}$} & \multirow{2}{*}{ Uso } & \multicolumn{4}{|c|}{ Controle $(\%)$} \\
\hline & & & & $30^{2 /}$ & 38 e $8^{3 /}$ & 49 e $19^{2 /}$ & 60 e $30^{2 /}$ \\
\hline 1. metolachlor + atrazine & $\mathrm{DC}+\mathrm{FS}$ II & $1,35+0,9$ & PRÉ & 91,25 & $88,75 \mathrm{a}^{3 /}$ & $88,75 \mathrm{a}^{3 /}$ & $88,75 \mathrm{a}^{3 /}$ \\
\hline 2. atrazine + atrazine $^{4 /}$ & FS II + FS II & $1,75+0,75$ & PRÉ/PÓS & 95,00 & $93,75 \mathrm{a}$ & $95,00 \mathrm{a}$ & $96,25 \mathrm{a}$ \\
\hline 3. atrazine $e^{4 /}$ & FS II & 2,5 & PÓS & - & $97,25 \mathrm{a}$ & $97,25 \mathrm{a}$ & $97,50 \mathrm{a}$ \\
\hline 4. nicosulfuron & ALS & 0,6 & PÓS & - & $0,00 \mathrm{c}$ & $25,00 \mathrm{c}$ & $5,00 \mathrm{c}$ \\
\hline 5. nicosulfuron + atrazine & ALS + FS II & $0,4+1,0$ & PÓS & - & $58,75 \mathrm{~b}$ & $65,50 \mathrm{~b}$ & $53,00 \mathrm{~b}$ \\
\hline 6. testemunha sem capina & & - & - & 0,00 & $0,00 \mathrm{c}$ & $0,00 \mathrm{~d}$ & $0,00 \mathrm{c}$ \\
\hline 7. testemunha com capina & & - & - & 100,00 & $100,00 \mathrm{a}$ & $100,00 \mathrm{a}$ & $100,00 \mathrm{a}$ \\
\hline $\mathrm{CV} \%$ & & - & - & - & 12,40 & 12,00 & 17,66 \\
\hline DMS 5\% & & - & - & - & 18,144 & 18,883 & 25,958 \\
\hline
\end{tabular}

1/ DC = divisão celular; FS II = fotossistema II; ALS = acetolactato sintase. ํㅚ Dias após a aplicação do pré e pós-emergente, respectivamente. ${ }^{3 /}$ Médias seguidas pela mesma letra, na coluna, não diferem entre si pelo teste de Tukey $(\mathrm{P}<5 \%) .{ }^{4 /}$ Óleo mineral - Assist $0,2 \% \mathrm{v} / \mathrm{v}$.

Tabela 3 - Biomassa seca, altura de picão-preto (B. subalternans) e rendimento da cultura de milho. Experimento de campo. Sertaneja-PR. Embrapa Soja. Londrina-PR. 2001

\begin{tabular}{|c|c|c|c|c|c|}
\hline Tratamento & $\begin{array}{c}\text { Dose } \\
\left(\mathrm{kg} \mathrm{ha}^{-1}\right)\end{array}$ & Uso & $\begin{array}{l}\text { Altura }^{1 /} \\
\quad(\mathrm{cm})\end{array}$ & $\begin{array}{c}\text { Biomassa }^{1 /} \\
\text { Seca }(g)\end{array}$ & $\begin{array}{l}\text { Rendimento } \\
\left(\mathrm{kg} \mathrm{ha}^{-1}\right)\end{array}$ \\
\hline 1. metolachlor + atrazine & $1,35+0,9$ & PRÉ & $5,50 \mathrm{bc}^{2 /}$ & $0,99 \mathrm{c}^{2 /}$ & $5.814 \mathrm{a}^{\frac{2}{-}}$ \\
\hline 2. atrazine + atrazine & $1,75+0,75$ & PRÉ/PÓS & $4,00 \mathrm{c}$ & $0,39 \mathrm{c}$ & $5.235 \mathrm{a}$ \\
\hline 3. atrazine & 2,5 & PÓS & $4,50 \mathrm{bc}$ & $0,34 \mathrm{c}$ & $5.072 \mathrm{a}$ \\
\hline 4. nicosulfuron & 0,6 & PÓS & $10,75 \mathrm{a}$ & $11,69 \mathrm{a}$ & $5.299 \mathrm{a}$ \\
\hline 5. nicosulfuron + atrazine & $0,4+1,0$ & PÓS & $7,25 \mathrm{~b}$ & $3,33 \mathrm{bc}$ & $5.974 \mathrm{a}$ \\
\hline 6. testemunha sem capina & - & - & $11,00 \mathrm{a}$ & $6,13 b$ & $5.426 \mathrm{a}$ \\
\hline 7. testemunha com capina & - & - & $0,00 \mathrm{~d}$ & $0,00 \mathrm{c}$ & $5.894 \mathrm{a}$ \\
\hline $\mathrm{CV} \%$ & - & - & 20,01 & 62,85 & 16,28 \\
\hline DMS $5 \%$ & - & - & 2,871 & 4,801 & $2.011,443$ \\
\hline
\end{tabular}

${ }^{1 /}$ Realizada 20 dias após a aplicação dos herbicidas pós-emergentes. 르 Médias seguidas pela mesma letra, na coluna, não diferem entre si pelo teste de Tukey $(\mathrm{P}<5 \%)$.

No experimento realizado a campo com milho, nicosulfuron não controlou o biótipo considerado resistente (Tabela 2). A mistura com atrazine elevou o controle, porém em nível considerado não-aceitável. É possível que a dose de atrazine utilizada tenha sido insuficiente, devido à quase total ausência de eficiência do inibidor da ALS. O resultado obtido permite especular sobre as vantagens da associação dos herbicidas, em relação ao uso isolado de nicosulfuron, desde que seja aumentada a dose de atrazine. A atrazine, em dose única, em aplicação seqüencial e em mistura com metolachlor, apresentou controle que variou de 88 a 97\%, indicando haver alternativas para o controle de plantas resistentes também nessa cultura (Tabela 2). Convém ressaltar que casos de resistência aos herbicidas inibidores da fotossíntese e da divisão celular foram registrados em outros países (Heap, 2001), o que indica a necessidade do manejo adequado para evitar a possibilidade da ocorrência de resistência múltipla. 
Tabela 4 - Tratamentos utilizados e avaliação visual da eficácia de herbicidas aplicados em pré e pós-emergência, na cultura da soja, no controle de picão-preto (B. subalternans) Experimento de campo. Sertaneja-PR. Embrapa Soja. Londrina-PR. 2001

\begin{tabular}{|c|c|c|c|c|c|c|c|}
\hline \multirow{2}{*}{ Tratamento } & \multirow{2}{*}{$\begin{array}{l}\text { Mec. de } \\
\text { Ação }^{1 /}\end{array}$} & \multirow{2}{*}{$\begin{array}{c}\text { Dose } \\
\left(\mathrm{kg} \mathrm{ha}^{-1}\right)\end{array}$} & \multirow{2}{*}{ Uso } & \multicolumn{4}{|c|}{ Controle $(\%)$} \\
\hline & & & & $30^{2 /}$ & 38 e $8^{3 /}$ & 49 e $19^{2 /}$ & 60 e $30^{2 /}$ \\
\hline 1. diclosulan & ALS & 0,035 & PRÉ & 27,50 & $7,50 \mathrm{~d}^{4 /}$ & $25,00 \mathrm{~d}^{4 /}$ & $25,00 \mathrm{bc}^{4 /}$ \\
\hline 2. diclosulan + fomesafen ${ }^{3 /}$ & ALS + Protox & $0,035+0,15$ & PRÉ/PÓS & 27,50 & $75,00 \mathrm{~b}$ & $83,75 \mathrm{ab}$ & $92,75 \mathrm{a}$ \\
\hline 3. imazethapyr + chlorimuron & ALS + ALS & $0,04+0,012$ & PÓS & - & $0,00 \mathrm{~d}$ & $30,00 \mathrm{~d}$ & $32,50 \mathrm{bc}$ \\
\hline 4. imazethapyr + oxasulfuron ${ }^{3 /}$ & ALS + ALS & $0,04+0,012$ & PÓS & - & $0,00 \mathrm{~d}$ & $20,00 \mathrm{~d}$ & $22,50 \mathrm{c}$ \\
\hline 5. oxasulfuron ${ }^{3}+$ fomesafen & ALS + Protox & $0,012+0,15$ & PÓS & (3)- & $68,75 \mathrm{~b}$ & $82,50 \mathrm{~b}$ & $90,75 \mathrm{a}$ \\
\hline 6. oxasulfuron ${ }^{3 /}$ & ALS & 0,02 & PÓS & (3) - & $0,00 \mathrm{~d}$ & $17,50 \mathrm{~d}$ & $20,00 \mathrm{c}$ \\
\hline 7. oxasulfuron ${ }^{3 /}+$ oxasulfuron $^{3 /}$ & ALS + ALS & $0,01+0,01$ & PÓS Seq. & - & $0,00 \mathrm{~d}$ & $26,25 \mathrm{~d}$ & $26,25 \mathrm{bc}$ \\
\hline 8. fomesafen & Protox & 0,25 & PÓS & & $80,00 \mathrm{~b}$ & $88,75 \mathrm{ab}$ & $95,75 \mathrm{a}$ \\
\hline 9. fomesafen ${ }^{3 /}+$ fomesafen $^{3 /}$ & Protox + Protox & $0,15+0,10$ & PÓS Seq. & & $72,50 \mathrm{~b}$ & $99,00 \mathrm{ab}$ & $100,00 \mathrm{a}$ \\
\hline 10. lactofen & Protox & 0,168 & PÓS & & $100,00 \mathrm{a}$ & $100,00 \mathrm{a}$ & $100,00 \mathrm{a}$ \\
\hline 11. lactofen + oxasulfuron & Protox + ALS & $0,12+0,012$ & PÓS & & $100,00 \mathrm{a}$ & $100,00 \mathrm{a}$ & $100,00 \mathrm{a}$ \\
\hline 12. testemunha sem capina & & - & - & & $0,00 \mathrm{~d}$ & $0,00 \mathrm{e}$ & $0,00 \mathrm{~d}$ \\
\hline 13. testemunha com capina & & - & - & & $100,00 \mathrm{a}$ & $100,00 \mathrm{a}$ & $100,00 \mathrm{a}$ \\
\hline $\mathrm{CV} \%$ & & & & & 13,70 & 11,63 & 10,82 \\
\hline DMS $5 \%$ & & & & & 15,88 & 17,30 & 16,50 \\
\hline
\end{tabular}

${ }^{1 /}$ ALS - inibidores da enzima acetolactato sintase; Protox - inibidores da enzima protoporfirinogênio oxidase. ${ }^{2 /}$ Dias após a aplicação do pré e pós-emergente, respectivamente. ${ }^{3 /}$ Adicionado $0,2 \%$ de Agral v/v. ${ }^{4 /}$ Médias seguidas pela mesma letra, na coluna, não diferem entre si pelo teste de Tukey $(\mathrm{P}<5 \%)$.

Tabela 5 - Densidade, altura, biomassa seca de plantas de picão-preto (Bidens subalternans) e rendimento da cultura da soja. Experimento de campo. Sertaneja-PR. Embrapa Soja. Londrina-PR. 2001

\begin{tabular}{|c|c|c|c|c|c|c|}
\hline Tratamento & $\begin{array}{c}\text { Dose } \\
\left(\mathrm{g} \text { i.a. } \text { ha }^{-1}\right)\end{array}$ & Uso & $\begin{array}{c}\text { № de } \\
\text { Plantas }^{\underline{1}}\end{array}$ & $\begin{array}{l}\text { Altura Planta } \\
\quad(\mathrm{cm})\end{array}$ & $\begin{array}{c}\text { Biomassa }^{1 /} \\
\text { Seca } \\
(\mathrm{g})\end{array}$ & $\begin{array}{l}\text { Rendimento } \\
\qquad\left(\mathrm{kg} \mathrm{ha}^{-1}\right)\end{array}$ \\
\hline 1. diclosulan & 0,035 & PRÉ & $182,75 \mathrm{ab}^{2 /}$ & $9,50 \mathrm{a}$ & $2,94 \mathrm{ab}$ & $2.743 \mathrm{ab}^{2 /}$ \\
\hline 2. diclosulan + fomesafen & $0,035+0,15$ & PRÉ/PÓS & $87,00 \mathrm{~b}$ & $4,50 \mathrm{c}$ & $0,82 \mathrm{~b}$ & $2.917 \mathrm{ab}$ \\
\hline 3. imazethapyr + chlorimuron & $0,04+0,012$ & PÓS & $176,25 \mathrm{ab}$ & $8,00 \mathrm{ab}$ & $2,95 \mathrm{ab}$ & $2.811 \mathrm{ab}$ \\
\hline 4. imazethapyr + oxasulfuron & $0,04+0,012$ & PÓS & $340,75 \mathrm{a}$ & $8,25 \mathrm{ab}$ & $6,40 \mathrm{a}$ & $2.534 \mathrm{ab}$ \\
\hline 5. oxasulfuron + fomesafen & $0,012+0,15$ & PÓS & $147,00 \mathrm{ab}$ & $5,50 \mathrm{bc}$ & $1,18 \mathrm{~b}$ & $2.517 \mathrm{ab}$ \\
\hline 6. oxasulfuron & 0,02 & PÓS & $353,25 \mathrm{a}$ & $10,50 \mathrm{a}$ & $6,47 \mathrm{a}$ & $2.339 \mathrm{~b}$ \\
\hline 7. oxasulfuron + oxasulfuron & $0,01+0,01$ & PÓS Seq. & $289,25 \mathrm{ab}$ & $11,25 \mathrm{a}$ & $5,05 \mathrm{ab}$ & $2.822 \mathrm{ab}$ \\
\hline 8. fomesafen & 0,25 & PÓS & $67,00 \mathrm{~b}$ & $3,75 \mathrm{c}$ & $0,63 \mathrm{~b}$ & $2.554 \mathrm{ab}$ \\
\hline 9. fomesafen + fomesafen & $0,15+0,10$ & PÓS Seq. & $0,00 \mathrm{c}$ & $0,00 \mathrm{~d}$ & $0,00 \mathrm{c}$ & $2.439 \mathrm{~b}$ \\
\hline 10. lactofen & 0,168 & PÓS & $0,00 \mathrm{c}$ & $0,00 \mathrm{~d}$ & $0,00 \mathrm{c}$ & $2.643 \mathrm{ab}$ \\
\hline 11. lactofen + oxasulfuron & $0,12+0,012$ & PÓS & $0,00 \mathrm{c}$ & $0,00 \mathrm{~d}$ & $0,00 \mathrm{c}$ & $2.903 \mathrm{ab}$ \\
\hline 12. testemunha sem capina & - & - & $359,25 \mathrm{ab}$ & $11,00 \mathrm{a}$ & $6,14 a b$ & $2.327 \mathrm{~b}$ \\
\hline 13. testemunha com capina & - & - & $0,00 \mathrm{c}$ & $0,00 \mathrm{~d}$ & $0,00 \mathrm{c}$ & $2.401 \mathrm{~b}$ \\
\hline $\mathrm{CV} \%$ & & & 47,09 & 23,23 & 55,62 & 13,10 \\
\hline DMS $5 \%$ & & & 226,63 & 3,40 & 4,49 & 881,67 \\
\hline
\end{tabular}

${ }^{1 /}$ Dados referentes a plantas daninhas: avaliação realizada 20 dias após a aplicação. ${ }^{2 /}$ Médias seguidas pela mesma letra, na coluna, não diferem entre si pelo teste de Tukey $(\mathrm{P}<5 \%)$. 
Apesar das diferentes percentagens de controle e da alta infestação de B. subalternans, não foram observadas diferenças no rendimento do milho (Tabela 3), nem mesmo sintomas visuais de fitointoxicação. Ao se incluir um produto com mecanismo de ação diferente da ALS, a biomassa seca da planta daninha foi reduzida. Aparentemente, nas parcelas sem herbicidas, as plantas daninhas apresentavam desenvolvimento lento e alta sensibilidade ao sombreamento, contrariando a afirmativa de Rizzardi et al. (2002) sobre o comportamento ecofisiológico similar de biótipos resistentes e suscetíveis, muito embora tenha ocorrido alteração genética e enzimática. Conard \& Radosevich (1979) verificaram que a produção de matéria seca de Senecio vulgaris e Amaranthus retroflexus de biótipos resistentes ao herbicida atrazine foi menor do que a do biótipo suscetível.

No experimento de campo com a soja, os herbicidas diclosulan, imazethapyr em mistura com chlorimuron e com oxasulfuron e oxasulfuron sozinho, em dose única ou em aplicação seqüencial não apresentaram controle eficiente sobre o biótipo resistente (Tabela 4). Portanto, todos os produtos com o mesmo mecanismo de ação proporcionaram resultados semelhantes, confirmando os resultados encontrados no experimento em casa de vegetação. Os herbicidas inibidores da enzima PROTOX, isoladamente ou em mistura com oxasulfuron, garantiram elevados níveis de controle (Tabela 4). Em todas as etapas conduzidas nesse experimento observou-se sempre a reduzida eficiência dos herbicidas que inibem a ALS e a melhoria de controle das plantas ao se alternar o mecanismo de ação dos herbicidas ou misturar produtos com diferentes mecanismos de ação. Outros trabalhos conduzidos no Brasil também relataram a ocorrência de resistência cruzada aos herbicidas inibidores da ALS (Gazziero et al., 1998; Vidal \& Merotto Jr., 1999). Na avaliação realizada 20 dias após a aplicação dos produtos de pós-emergência, verificou-se que a biomassa seca e a altura das invasoras foram significativamente menores nos tratamentos que continham herbicidas com mecanismo de ação diferenciado da ALS (Tabela 5). Entretanto, apesar de terem apresentado controle, nem todos os tratamentos conseguiram matar a totalidade das plantas, embora tenham provocado forte efeito supressor. Na cultura, não foi observada fitointoxicação superior a $10 \%$. O resultado no rendimento de grãos não evidenciou diferenças que pudessem ser atribuídas aos tratamentos. Após o início do estádio reprodutivo da soja, as plantas daninhas começaram a morrer em todas as parcelas, influenciadas pelo controle cultural. Da mesma forma que no experimento de milho, aparentemente, as plantas de picão-preto resistentes mostraram desenvolvimento lento. O biótipo de Lactuca serriola resistente aos herbicidas do grupo químico das sulfoniluréias apresentou menor taxa de crescimento do que o biótipo suscetivel (Alocer-Ruthling et al., 1992), o que permite suspeitar sobre a influência desse tipo de alteração sobre os resultados encontrados. No entanto, trabalhos conduzidos no Brasil por Brighenti et al. (2001), com Euphorbia heterophylla, e por Christoffoleti (2001), com Bidens pilosa, não mostraram diferenças quanto ao crescimento de biótipos considerados suscetiveis e resistentes aos inibidores da ALS.

Os resultados encontrados neste trabalho permitiram as seguintes conclusões:

a) A população de Bidens subalternans da área experimental era composta por biótipos resistentes aos herbicidas inibidores da ALS.

b) Produtos com mecanismo de ação diferenciado, utilizados isoladamente ou em mistura com inibidores da ALS, apresentam eficiência de controle sobre o biótipo resistente.

c) Herbicidas inibidores da ALS controlam eficientemente o biótipo considerado suscetivel.

d) Existem alternativas químicas, tanto na cultura da soja como na do milho, para manejar áreas com problemas de biótipos resistentes aos inibidores da ALS.

\section{AGRADECIMENTO}

Aos técnicos Mário Nakano e Reinaldo Moriyama e aos funcionários Alvino Custódio Vieira, Silvio Salvador e José Olímpio Mota, pela cooperação na condução do trabalho e pela amizade. Ao Consherb, pela oportunidade de interação com professores e pesquisadores.

Planta Daninha, Viçosa-MG, v.21, n.2, p.283-291, 2003 


\section{LITERATURA CITADA}

ALOCER-RUTHLING, M.; THILL, D. C.; SHAFII, B Differencial competitiveness of sulfonylureia resistant and susceptible prickly lettuce (Lactuca serriola). Weed Technol., v. 6, p. 303-309, 1992.

BRIGHENTI, A. M. et al. Análise do crescimento de biótipos de amendoim-bravo (Euphorbia heterophylla) resistente e suscetível aos herbicidas inibidores da enzima ALS. Planta Daninha, v. 19, n. 1, p. 51-60, 2001.

CHRISTOFFOLETI, P. J.; VICTORIA FILHO, R.; SILVA, C. B. Resistência de plantas daninhas aos herbicidas. Planta Daninha, v. 12, n. 1, p. 13-20, 1994.

CHRISTOFFOLETI, P. J. et al. Imidazolinona resistance Bidens pilosa biotypes in the Brazilian soybean areas. In: MEETING OF THE WEED SCIENCE OF SOCIETY OF AMERICA, 36., 1996, Norfolk. WSSA Abstracts... Champaing: WSSA, 1996. p. 10.

CHRISTOFFOLETI, P. J. Análise comparativa do crescimento de biótipos de picão-preto (Bidens pilosa) resistente e suscetível aos herbicidas inibidores da enzima ALS. Planta Daninha, v. 19, n. 1, p. 75-83, 2001.

CONARD, S. G.; RADOSEVICH, S. R. Ecological fitness of Senecio vulgaris and Amaranthus retroflexus biotypes susceptible or resistant to atrazine. J. Appl. Ecol., v. 16, p. 171-177, 1979.

EBERHARDT, D. S. et al. Resistência de capim-arroz (Echinocloa crusgalli) ao herbicida quinclorac. In: CONGRESSO BRASILEIRO DA CIÊNCIA DAS PLANTAS DANINHAS, 22., 2000, Foz do Iguaçu. Resumos... Foz do Iguaçu: SBCPD, 2000. p. 512.

GAZZIERO, D. L. P. et al. Resistência de biótipos de Brachiaria plantaginea aos herbicidas inibidores da ACCase aplicados em soja. In: CONGRESSO

BRASILEIRO DA CIÊNCIA DAS PLANTAS DANINHAS, 21., 1997, Caxambu. Resumos... Caxambu: SBCPD, 1997. p. 88.

GAZZIERO, D. L. P. et al. Levantamento preliminar da ocorrência de picão-preto (Bidens pilosa e Bidens subalternans) em áreas de cultivo de soja no Estado do Paraná. In: REUNIÃO DE PESQUISA DE SOJA DA REGIÃO CENTRAL DO BRASIL, 20., 1998, Londrina. Atas e Resumos... Londrina: Embrapa, 1998a.

GAZZIERO, D. L. P. et al. Resistência de amendoim-bravo aos herbicidas inibidores da enzima ALS. Planta Daninha, v. 16 , n. 2 , p. $118-125,1998$ b.

GAZZIERO, D. L. P. et al. Resistência da planta daninha capim-marmelada (Brachiaria plantaginea) aos herbicidas inibidores da enzima ACCase na cultura da soja. Planta Daninha v. 18, n. 1, p. 169-180, 2000.
GAZZIERO, D. L. P. et al. As plantas daninhas e a semeadura direta. Londrina: EMBRAPA Soja, 2001. 59 p. (Circular técnica, 33).

HEAP, I. International survey of herbicide-resistant weeds. Disponível em: http://weedscience.com. Acesso em: 19 nov. 2001.

KISSMANN, K. G.; GROTH, D. Plantas infestantes e nocivas. São Paulo: Basf Brasileira, 1993. 798 p. t. 2.

MEROTTO JR., A. et al. Resistência de Echinochloa sp. à quinclorac. In: CONGRESSO BRASILEIRO DA CIÊNCIA DAS PLANTAS DANINHAS, 22., 2000, Foz do Iguaçu. Resumos... Foz do Iguaçu: SBCPD, 2000. p. 513.

MONQUEIRO, P. A.; CHRISTOFFOLETI, P. J.; DIAS, C. T. S. Resistência de plantas daninhas aos herbicidas inibidores da ALS na cultura da soja. Planta Daninha v. 18 , n. 3, p. 419-425, 2000.

MONQUEIRO, P. A.; CHRISTOFFOLETI, P. J. Manejo de populações de plantas daninhas resistentes aos herbicidas inibidores da acetolactato sintase. Planta Daninha, v. 19, n. 1, p. 67-74, 2001.

NOLDIN, J. A. et al. Sagitaria resistente a herbicidas inibidores da enzima ALS. In: CONGRESSO BRASILEIRO DA CIÊNCIA DAS PLANTAS DANINHAS, 22., 2000, Foz do Iguaçu. Resumos... Foz do Iguaçu: SBCPD, p. 514. 2000 .

OLIVEIRA JR., R. S. Mecanismo de ação de herbicidas. In: OLIVEIRA Jr, R.S.; CONSTANTIN, J. (Coord.). Plantas daninhas e seu manejo. Guaíba: Agropecuária, 2001. p. 209-260.

PONCHIO, J. A. R. et al. ALS enzyme assay from Bidens pilosa biotypes of the Brazilian soybean areas to determine the sensitivy to imidazolinone and sulfonilurea herbicides. In: MEETING OF THE WEED SCIENCE SOCIETY OF AMERICA, 36., 1996, Norfolk. Abstracts... Champaign: WSSA, 1996. p. 79.

POWLES, S. B.; HOWAT, P. D. Herbicide resistence weeds in Australia. Weed Technol., v. 4, p. 178-185, 1990.

RIZZARDI, M. A. et al. Resistência de plantas aos herbicidas inibidores da acetolactato sintase. Planta Daninha, v. 20, n. 1, p. 149-158, 2002.

SOCIEDADE BRASILEIRA DA CIÊNCIA DAS PLANTAS DANINHAS - SBCPD. Comitê Brasileiro de Resistência de Plantas aos Herbicidas. Identificação e manejo de plantas daninhas resistentes aos herbicidas. Londrina: 2000. $32 \mathrm{p}$.

TRANEL, P. J.; WRIGHT, T. R. Resistance of weeds to ALS herbicides: What have we learned? Weed Sci., v. 50, v. 6 , p. 700-712, 2002. 
TREZZI, M. M.; VIDAL, R. A. Herbicidas inibidores da ALS. In: VIDAL, R.A.; MEROTTO JR, A. (Eds.) Herbicidologia. Porto Alegre: R.A. Vidal \& Merotto Jr., 2001. p. 25-36.

VARGAS, L. et al. Resistência de plantas daninhas a herbicidas. Viçosa, MG: Universidade Federal de Viçosa, 1999. $131 \mathrm{p}$.

VIDAL, R. A. Herbicidas: mecanismo de ação e resistência de plantas. Porto Alegre: Palotti, 1997. 165 p.
VIDAL, R. A.; FLECK, N. G. Three weed species with confirmed resistance to herbicides in Brazil. In: MEETING OF THE WEED SCIENCE SOCIETY OF AMERICA, 37., 1997. Orlando. Weed Abstracts... Champaing: WSSA, 1997. p. 100.

VIDAL, R. A.; MEROTTO JR., A. Resistência de amendoim-bravo aos herbicidas inibidores da enzima acetolactato sintase. Planta Daninha, v. 17, n. 3, p. $367-$ 373, 1999. 